

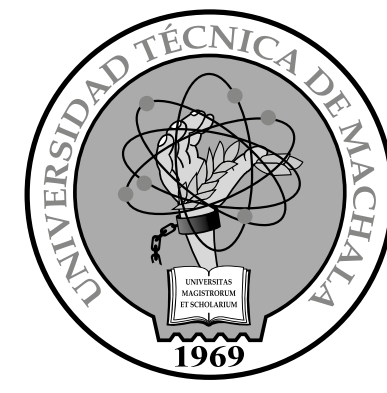

(c) (i) ()

Ediciones UTMACH 86 pág: $21 \times 25,5 \mathrm{~cm}$

Colección Semana de la Ciencia

Título: Procesos estratégicos y finanzas populares en los emprendimientos - Lady León Serrano (Compiladora)

Primera edición - junio 2021

ISBN: 978-9942-24-144-3

CDD 336

1. Economía,

2. Empresa y gestión

--Temas relacionados

Publicación PDF 


\section{Procesos estratégicos y finanzas populares en los emprendimientos}


Lady León-Serrano

COMPILADORA 
César Quezada Abad - Rector

Amarilis Borja Herrera - Vicerrector Académico

Jhonny Pérez Rodríguez - Vicerrector Administrativo

Luis Brito Gaona

Director de Investigación

(c) Ediciones UTMACH

Colección Semana de la Ciencia

Título original:

Procesos estratégicos y finanzas populares en los emprendimientos

ISBN: 978-9942-24-144-3

DOI: http://doi.org/10.48190/9789942241443

Libro con revisión de pares ciegos especializados

(c) Lady León-Serrano

(Compiladora)

(c) Autores de capítulos

Karina Lozano Zambrano Jefe editor / Diseño y edición editorial Edison Mera León - Diseño de portada

Fernanda Tusa Jumbo - Corrector de estilos Jorge Maza-Cordova - Asesor tecnológico Karla Ibañez y Cyndi Aguilar - Equipo de difusión

Primera edición Junio 2021 Machala-Ecuador

Universidad Técnica de Machala - UTMACH Correo: editorial@utmachala.edu.ec Licencia Creative Commons Atribución-NoComercial-CompartirIgual 4.0 Internacional (CC BY-NC-SA 4.0). 


\section{Contenido}

Gestión por procesos como herramienta estratégica en las pequeñas y medianas empresas

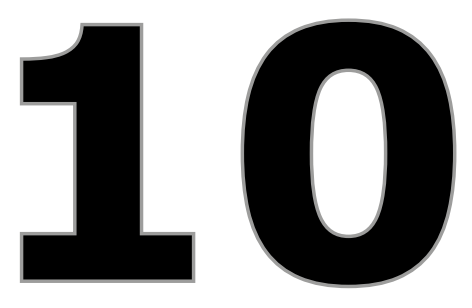

Finanzas populares y solidarias como alternativas para el desarrollo en los emprendimientos de eocnomía popular y solidaria en la ciudad de Machala, 2019

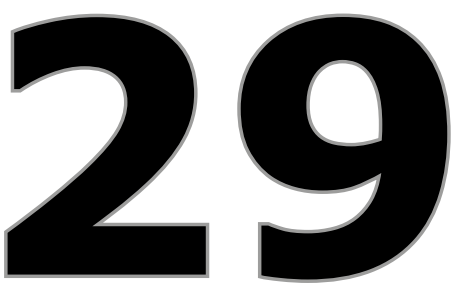

Los emprendedores y el poder de adaptación en los tiempos de pandemia
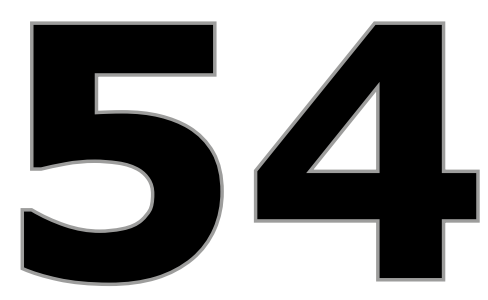

Pág. 


\section{Introducción}

El desarrollo de los emprendimientos es considerado un factor estratégico para el avance económico, comercial y solidario de los países, el aporte de nuevos negocios con productividad ha generado empleo y valor agregado a las economías, sin embargo, los diversos problemas de competitividad que enfrentan afecta la capacidad de sobrevivencia, sin duda el progreso de los mercados conformados en gran parte por las pequeñas y medianas empresas implica adaptación de instrumentos globales que permitan perfeccionar las habilidades gerenciales y organizacionales desde los procesos vinculantes con buenas prácticas y mejora continua.

En este sentido, la organización y permanencia del núcleo emprendedor permite hacer frente ante los factores externos, creando alternativas con elementos estratégicos, enfoques sistemáticos confiables y característicos en la toma de decisiones, en base a la intensionalidad de crear incentivos favorables propios de los actores sociales, aprovechando las fortalezas del entorno con programas de apoyo financiero, no financiero, acceso a nuevas fuentes de aprovisionamiento y condiciones socioeconómicas.

Consecuentemente, la transformación de los emprendimientos desde una masificación internacional y nacional ha requerido del impulso de políticas públicas con tratamientos de gestión y control interno, más allá de un margen estratégico de comercialización, se asocia con las finanzas populares y solidarias en la plena capacidad de planificar y regular el interés general, asumiendo un rol protagónico de intermediación y prestación de servicios financieros entre sí. Así, el fomento de la producción tiene un sentido cooperativo, con igualdad de derechos y participación. 
El impacto de la dinámica del conocimiento e innovación de los productos y servicios demanda cada vez la satisfacción de necesidades locales. El comportamiento del comercio global, competidores y clientes, constantemente presentan variaciones en los planes estratégicos con un pensamiento de comercio justo, equitativo y sostenibilidad en el tiempo.

Los factores externos llevan a profundizar la resiliencia de las perqueñas y medianas empresas, aquellos emprendedores trastocados por la pandemia generada por el Covid-19 junto a los momentos de incertidumbre han puesto en marcha nuevas habilidades en el uso de recursos tecnológicos y empoderamiento social, marcando la crisis como una oportunidad.

El aporte intelectual de la presente obra, parte de la Colección Semana de la Ciencia de la Editorial Utmach, contribuye en la difusión de conocimientos sobre los procesos estratégicos y finanzas populares, y la claridad de emprender en tiempos de pandemia desde la innovación tecnológica sustentado en las bases teóricas y la cuantificación de datos para la ejemplaridad reflexiva del lector en el alcance de la visualización y posicionamiento internacional. 



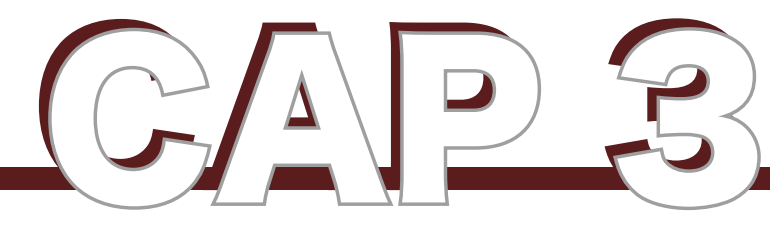

\title{
Los emprendedores y el poder de adaptación en los tiempos de pandemia
}

\author{
Irene Feijoo Jaramillo \\ Manuel López Feijoo \\ Ximena Pereira Feijoo \\ Edinson Valarezo Alvear
}




\section{AUTORES}

\section{Irene Feijoo Jaramillo}

Universidad Técnica de Machala / ifeijoo@utmachala.edu.ec

Machala - Ecuador

\section{Manuel López Feijoo}

Universidad Técnica de Machala / malopez@utmachala.edu.ec

Machala - Ecuador

\section{Ximena Pereira Feijoo}

Universidad Técnica de Machala / xpereira1@utmachala.edu.ec

Machala - Ecuador

\section{Edinson Valarezo Alvear}

Universidad Técnica de Machala / evalarezo4@utmachala.edu.ec Machala - Ecuador 


\section{Los emprendedores y el poder de adaptación en los tiempos de pandemia}

\section{Resumen}

Ecuador en los meses de marzo y abril enfrentó una de las situaciones más críticas del año 2020, debido a la extensión de la pandemia global conocida como COVID-19, siendo la principal causa para el desarrollo de una crisis económica global, debido a esto, el objetivo del presente estudio consiste en analizar la adaptación que tuvieron los emprendedores, al desarrollar micro-negocios en tiempos de pandemia, a través de un estudio cualitativo, en el que se describen las ventajas y desventajas presentadas al momento de emprender, en una situación de crisis económica como la que atraviesa el país.

La metodología desarrollada se sustentó en un formato de entrevista realizado a 10 de los nuevos emprendimientos detectados en la ciudad de Machala en la que se tomó en consideración variables como: idea del negocio, barreras, oportunidades y amenazas, ventajas competitivas, estrategias de marketing y aprendizajes obtenidos. Como resultado, se ha determinado un incremento de emprendimientos en los meses de mayo y julio de 2020. Además, la motivación a emprender radica en el deseo de superación que poseen los emprendedores entrevistados y la iniciativa de obtener un ingreso extra que favorezca la economía familiar, finalmente se destaca que los emprendedores, son individuos con la capacidad de adaptarse a las circunstancias que exige el mercado, viéndose en una situación de riesgo, buscaron respuestas inmediatas y eficaces, para poder sobrellevar sus actividades, apoyándose en herramientas digitales, las cuales facilitaron la comunicación y comercialización de sus productos hacia su segmento meta.

Palabras claves: Emprendimiento, pandemia, marketing. 


\section{Introducción}

En los últimos años el Ecuador ha afrontado una situación difícil en su factor económico, a causa de las malas decisiones tomadas por antiguos gobiernos, debido al derroche financiero, teniendo como consecuencia un incremento en el gasto público, frente a esto el déficit fiscal y la deuda pública también aumentaron considerablemente, puesto que actualmente el valor de la deuda es de 59.250 millones de dólares, es decir en un año subió cerca de 10 mil millones de dólares, motivo por el cual bordea los 60 mil millones de dólares, sin embargo esta situación se ha tratado de revertir, con las exportaciones de banano, cacao, flores, camarón, entre otros, sin embargo eso no fue suficiente para mantener al país en mejores condiciones (Vera et al., 2020).

Ante esto, surgieron problemas que se hicieron evidentes con la llegada del COVID-19, porque las personas tuvieron que aislarse durante un buen tiempo, algunos perdieron sus empleos, otros no recibieron su salario por el tiempo del confinamiento, las empresas que no pudieron solventar su situación económica tuvieron que cerrar, y es aquí donde realmente se puede notar que la situación del país se torna difícil, porque las condiciones de vida no son las mejores, y al mismo tiempo, por la desesperación de no tener dinero suficiente para su familia, debido a esta situación surgen las ganas de emprender, de luchar por alcanzar sus sueños, y no darse por vencidos, es justamente en este tiempo de pandemia donde se puede evidenciar un incremento en los emprendimientos, logrando formular bien sus ideas para que su proyecto se desarrolle adecuadamente.

En la provincia de El Oro han incrementado los emprendimientos en los meses de mayo y junio, esto se ha podido evidenciar a simple vista en redes sociales, siendo estos los medios más utilizados para dar a conocer dichos negocios, pese a esto, no se cuentan con porcentajes oficiales, puesto que no se han realizado investigaciones sobre los emprendimientos generados a nivel nacional, y en cada provincia, sin embargo, a información de (Eluniversocom, 2020) se detalla que el $82 \%$ de los ecuatorianos emprende a causa del desempleo, el $52,7 \%$ por querer marcar la diferencia, el $36,5 \%$ lo hace por acumular riquezas y el $35,7 \%$ por continuar con la tradición familiar, cabe destacar que con esto logran aportar en la economía no solo de la provincia, sino que también en la del país, debido a que es 
un pilar fundamental para la reactivación de la economía, pero para conseguir una estabilidad económica, deberán pasar algunos meses e incluso años hasta el término de la pandemia.

Los emprendedores ponen todo de ellos con la finalidad de alcanzar un óptimo desarrollo en sus negocios, tratando de encontrar una diferencia entre sus productos y los del mercado, logrando establecer una ventaja competitiva, por esta razón, el objetivo de la presente investigación consiste en analizar cómo micro emprendimientos han surgido en tiempos de pandemia, a través de una metodología cualitativa, que permita determinar sus pro y contras en el desarrollo de sus actividades económicas, esto se logró a través de una entrevista a 10 nuevos emprendedores para conocer aspectos o factores influyentes en sus negocios.

\section{Antecedentes}

\section{Declaración de la pandemia según la Organización Mundial de la Salud}

A partir del 11 de marzo del 2020, la vida de muchas personas cambió, cuando la Organización Mundial de la Salud OMS (Planificación.gob, 2020), declaró a la enfermedad del Coronavirus como una pandemia, pero ante esto es necesario conocer ¿qué es el coronavirus?, pues bien, es conocido como el síndrome respiratorio agudo grave, el mismo que se originó en China, exactamente en la ciudad de Wuhan, los síntomas de este virus pueden aparecer entre los 2 y 14 días de haberlo recibido, entre los síntomas más comunes de esta enfermedad se encuentran: fiebre, cansancio y tos, adicionalmente puede existir la pérdida del olfato y del gusto, es importante indicar que no todos están propensos a contagiarse con la misma carga viral, motivo por el cual la OMS pidió a los países que activen protocolos de seguridad para precautelar la salud de la población.

Esta enfermedad no solo afectó a los sistemas de salud, al contrario, afectó la economía de todo el mundo, porque existió una paralización en las actividades, se cerraron cines, restaurantes, gimnasios, discotecas, bares, centros de entrenamiento, parques, colegios, escuelas, universidades, entre otros, al principio únicamente funcionaban las empresas que abastecían de alimentos a la población, los hospitales y las clínicas. 


\section{Declaración de estado de excepción en Ecuador}

En Ecuador la situación fue igual que en el resto del mundo, el primer caso de coronavirus se diagnosticó el 29 de febrero de 2020, desde ese momento empezó a existir incertidumbre en las personas por el miedo al contagio, pese a esto el gobierno no tomó decisiones adecuadas, motivo por lo que aumentaron los contagios de manera progresiva, donde el 16 de marzo se declaró estado de excepción en el territorio ecuatoriano, la finalidad era evitar que el virus se siga propagando, se implementó toque de queda, se cerraron varias empresas, para que las personas eviten trasladarse, el sector del transporte también estuvo paralizado, fueron varios meses en los que la población tuvo que permanecer en sus casas para salvaguardar su vida, causando con esto que varias empresas con muchos años de trayectoria se vean en la obligación de cerrar definitivamente las puertas de sus negocios porque debido a la pandemia quebraron, entre estas se encuentran las de sector hotelero, porque por la pandemia se paralizó el turismo y sus habitaciones estuvieron prácticamente desocupadas y lo que obtuvieron de ingresos no les alcanzaba para seguir funcionando. A continuación, se detalla el porcentaje de pérdidas de acuerdo a los sectores:

Tabla 1. Porcentaje de pérdidas por sectores

\begin{tabular}{|c|c|}
\hline SECTOR & PORCENTAJE \% \\
\hline \multicolumn{2}{|l|}{ SOCIAL } \\
\hline Protección social & $1,2 \%$ \\
\hline Salud & $13,5 \%$ \\
\hline Cultura y deportes & $1,4 \%$ \\
\hline Educación & $4,1 \%$ \\
\hline TOTAL & $20,2 \%$ \\
\hline \multicolumn{2}{|l|}{ PRODUCTIVO } \\
\hline Pesca & $0,7 \%$ \\
\hline Industria & $8,6 \%$ \\
\hline Comercio & $30,8 \%$ \\
\hline Agropecuario & $5,6 \%$ \\
\hline
\end{tabular}




\begin{tabular}{|l|c||}
\hline \multicolumn{1}{|c|}{ Servicios } & $9,0 \%$ \\
\hline Turismo & $9,1 \%$ \\
\hline INFRAESTRUCTURA Y RECURSOS NATURALES \\
Transporte & $11,1 \%$ \\
\hline Agua y saneamiento & $1,2 \%$ \\
Medio ambiente & $0,9 \%$ \\
\hline Energía y comunicaciones & $2,4 \%$ \\
\hline TOTAL & $15,6 \%$ \\
\hline SEGURIDAD & \\
\hline Seguridad & $\mathbf{1 0 0 \%}$ \\
\hline Gestión de riesgos & $0,3 \%$ \\
TOTAL & $0,1 \%$ \\
\hline TOTAL DE PÉRDIDAS & $0,4 \%$ \\
\hline
\end{tabular}

Fuente: Elaboración propia (Planificación.gob, 2020)

Como se puede observar en la tabla 1 , el sector productivo fue el más afectado con un porcentaje del $63,8 \%$, de aquí se destaca un golpe grande al comercio con pérdidas del 30,8\%, siendo la cantidad de 1.978,34 millones de dólares, esto se conoce a través de un informe realizado por el gobierno ecuatoriano en el que se analiza la evaluación socioeconómica del país debido a la pandemia. Ante esto en una investigación realizada por (OIT, 2020) se explica que estas situaciones incrementaron el desempleo en donde la tasa del mismo subió del 9 al 10\%, lo que significó que al menos unas 500 mil personas se queden sin empleo, frente a esto el trabajo en el sector informal incrementó puesto que al menos unas 233 mil personas empezaron a trabajar de esta manera, en sí la enfermedad del coronavirus ha logrado desestabilizar a la economía y aún más generar pérdidas de vidas humanas. 


\section{Análisis del emprendimiento en el Ecuador antes del 16 de marzo}

Antes de la pandemia, en Ecuador se registraba un índice de Actividad Emprendedora Temprana (TEA) del 36.2\%, los valores para ese año fueron más altos que los del 2017 en el que se registró el 29,62\%; esto según los datos tomados de la ESPOL, en ese total de emprendimientos, se encontraban personas con estudios de segundo y tercer nivel, personas menores de 35 años y personas cuyos hogares percibían ingresos de 400 y 790 dólares.

Entre los motivos, por los que surgieron estos emprendimientos se encuentran los proyectos familiares, el desempleo, incrementar los ingresos y finalmente el perseguir o cumplir un sueño, pero lamentablemente con el surgimiento de la pandemia, algunos de estos emprendimientos tuvieron que dejar de funcionar.

\section{Análisis de la literatura}

Esta investigación tiene contextualizados puntos fundamentales para determinar cómo emprender, que estrategias de marketing utilizar, las redes sociales adecuadas para incrementar las ventas, las promociones y la selección adecuada de precios con los que una empresa puede lanzarse al mercado, a continuación, se determina cada uno de los temas:

\section{¿Qué es un emprendimiento?}

No existe una definición exacta sobre qué es un emprendimiento, pero según (Alemany et al., 2011) en su libro se indica que emprendimiento son aquellas acciones que nos llevan a emprender, llevar a cabo el desarrollo de nuevas ideas o de un negocio. En otras palabras, un emprendedor es aquella persona que a través de sus capacidades enfrenta el reto de crear su propio negocio, para esto se necesita tener visión, aceptación y estar consciente de los riesgos a los que se puede enfrentar en el mercado (Rodríguez et al., 2020).

\section{Características de un emprendimiento}

Para que un emprendimiento tenga aceptación en el mercado debe tener las siguientes características: 
Ser innovador: no se puede lanzar al mercado ofreciendo lo mismo que ofrecen las otras empresas, motivo por el cual es fundamental que en los nuevos emprendimientos se analice algo innovador que logre captar la atención del público.

Ser diferenciador: es importante establecer estrategias diferenciadoras de la competencia, de esta manera el emprendimiento podrá mantenerse en el mercado.

Tener la visión de expansión: al inicio del desarrollo del emprendimiento quizás no estén claras las ideas de expansión, pero esto es fundamental, porque ayudará a generar mayores ingresos y a poder consolidarse como un negocio más fuerte.

Utilizar la tecnología: en este punto nos referimos a la utilización de la tecnología en lo que conlleva a las redes sociales del emprendimiento, para darse a conocer con el público objetivo, a través de esto se crean relaciones con los clientes.

Implementación de estrategias de marketing: al referirnos a estrategias de marketing nos estamos direccionando por la parte publicitaria y promocional, puesto que sin esta característica el emprendimiento no va a tener mucha acogida, el uso adecuado de estrategias promocionales logrará captar la atención del cliente, este tema lo estaremos analizando detalladamente más adelante (Vélez \& Ortiz, 2016).

\section{Pasos para crear un emprendimiento}

- Para el desarrollo de un nuevo negocio es fundamental seguir ciertos pasos que permitirán que el emprendimiento funcione mejor:

- El paso inicial, es determinar la idea del negocio que se va a emprender.

- Como segundo paso se debe determinar por qué es importante que exista esta idea de negocio.

- Se debe realizar un análisis de la situación del mercado, además se deben analizar las nuevas tendencias.

- Como cuarto paso se encuentra el realizar un análisis para determinar por qué los consumidores adquirirían el nuevo producto o servicio.

- Realizar un análisis sobre el segmento de mercado del nuevo emprendimiento.

- Analizar y determinar los competidores y las ventajas diferenciadoras que se presenta.

- Detallar cómo será el producto que se quiere comercializar.

- Analizar los recursos que se van a necesitar para que la idea del negocio pueda desarrollarse. 
- Finalmente se debe analizar las prioridades de la idea del negocio y se debe tener el respaldo de planes financieros que permitan solventar de alguna manera el negocio.

\section{Etapas de un emprendimiento}

La mayoría de los emprendimientos pasan por etapas, pero al desarrollarse de manera empírica sus propietarios desconocen realmente en qué etapa del emprendimiento se encuentran, para esto se va a analizar cada etapa, las mismas que permitirán expandir los conocimientos sobre este tema:

- Gestación: esta es la fase inicial, porque aquí se empiezan a desarrollar las ideas de negocio, es decir el emprendedor en muchas de las ocasiones desconoce la etapa en la que se encuentra, únicamente desarrolla esto, de acuerdo a sus ganas por salir adelante y cumplir sus sueños.

- Puesta en marcha: en esta fase el emprendedor empieza a poner en marcha cada una de sus ideas, desarrolla el prototipo del producto que va a lanzar al mercado.

- Desarrollo: aquí ya se empieza a poder en práctica el modelo de negocio que se estableció previamente, el emprendedor empieza a formar relaciones con los clientes, buscando obtener aceptación en el mercado.

- Crecimiento: en esta fase ya las ideas se encuentran mucho más consolidadas, el emprendedor entiende bien lo que debe realizar, en esta fase la idea de negocio pasa de ser un emprendimiento para convertirse en una empresa.

- Internacionalización: en esta última fase el emprendedor ya tiene claro lo que debe realizar para que su empresa sea más exitosa y se expanda, el punto fundamental en esta fase es el financiamiento (Chirinos, Meriño, \& Martínez, 2018).

\section{¿Qué es un emprendedor?}

Por emprendedor se conoce a aquella persona que tiene previamente fijada una misión o meta que desea cumplir complementándolas con ideas de negocios innovadoras, motivo por el cual se deberán invertir tiempo y asumir riesgos que se presenten en el camino, para que esto funcione el emprendedor deberá ser creativo, persistente, a la vez tendrá que desarrollar un plan que le permita mantenerse en el mercado (Murulanda et al., 2019). 
Los emprendedores deben saber ejecutar acciones, realizar previamente controles para determinar si el producto es de calidad y logra satisfacer las necesidades de sus clientes, por lo tanto, debe mantener relaciones cercanas con su segmento de mercado, de la misma manera debe implementar estrategias y establecer promociones que logren captar la atención del público y que generen lealtad de los clientes frecuentes (Zamora, 2018).

En sí un emprendedor debe encargarse de manera proactiva de todas las actividades que se sean necesarias para que la idea de negocio se pueda planificar, ejecutar, controlar y evaluar. Una de las actividades más importantes del emprendedor es tener una ventaja diferenciadora de la competencia.

\section{Características de un emprendedor}

Para que un emprendedor pueda desempeñarse bien debe tener ciertas características que se consideran importantes, porque son ellas que le permitirán que cada una de las decisiones que tomen se desarrollen adecuadamente, entre las características del emprendedor se encuentran las siguientes:

- Capacidad organizativa: son aquellas actividades como la planificación, la coordinación de recursos y de tiempo; y el establecimiento de plazos que debe encargarse de organizar el emprendedor.

- Analítico: la parte fundamental de esta característica es que el emprendedor busca la seguridad, es decir, antes de querer tomar una decisión se informa, ya sea de la situación en el mercado, de las ventajas o desventajas que como futuro emprendedor podría tener en el mercado.

- Optimista: el emprendedor debe ser positivo y asumir nuevos retos, esto servirá para que pueda salir de su zona de confort.

- Dinámico: debe tener energía, estar dispuesto a enfrentar cada reto propuesto con el mejor humor y ánimo, de esta manera las actividades serán con una carga menos.

- Entusiasta: un emprendedor debe ser guiado por la sabiduría y la fuerza necesaria para que pueda enfrentar cada reto, que se le presente al momento de emprender.

- Creativo: el emprendedor debe generar nuevas ideas y debe tener mucha creatividad, al momento de hacer que sus productos sean diferentes a la competencia. 
- Capacidad para asumir riesgos: es importante que el prendedor, tenga claro que no todas las actividades que va a desarrollar en la empresa será fáciles, al contrario, debe estar consciente de que emprender puede traer momentos buenos y malos, los mismos que se los deberá afrontar de la mejor manera.

- Orientado al crecimiento: esta característica es importante, porque la idea del emprendedor no debe quedarse estancada, debe tener una visión y una meta a la que se quiera llegar, así mismo se debe plantear el crecer en el mercado (Jácome et al., 2018).

\section{Desafíos de un emprendedor:}

Según Martínez \& Bañón (2020), los emprendedores al momento de poner en práctica su idea de negocio tienen los siguientes desafíos:

- Digitalización: antes de la pandemia se utilizaban medios digitales para dar a conocer los productos o servicios de la empresa, pero fue justamente en tiempos de pandemia donde el uso de estos medios se hizo más común e importante, porque las personas al no poder salir de casa, utilizaban en mayor proporción redes sociales, o aplicaciones, frente a esto las empresas y los nuevos emprendedores tuvieron que adaptarse para poder llevar sus ideas de negocio a través de Facebook, WhatsApp, Instagram, Tik Tok, Google Ads, entre otros, el ingenio y la creatividad son fundamentales, puesto que de eso depende la aceptación de la audiencia.

- Financiación: el COVID-19 llegó y afectó directamente la parte económica de los ecuatorianos y del mundo entero, ante esto, grandes empresas cerraron, he aquí el desafío de los nuevos emprendedores, el poder conseguir financiamiento para llevar a cabo el desarrollo de sus productos o servicios.

- Percepción de oportunidades: los emprendedores suelen percibir las oportunidades y saber elegir el mercado al que se dirigen, los precios y aquellas estrategias que puedan utilizar para que su idea de negocio tenga acogida del público. Frente a esto (Schumpeter, 2012) realiza un análisis importante puesto que indica que los gobiernos no suelen reaccionar de la manera adecuada ante situaciones de crisis, imposibilitando la opción de tener una rápida recuperación y no aprovechando las oportunidades que se les presenten.

- Capital humano: la pandemia provocó que exista falta de capital humano, puesto que al estar saturados los hospitales los médicos se sintieron saturados, provocando 
que muchos de ellos se enfermen y que exista falta de profesionales que ayuden a combatir esta situación, esto ayudó a comprender que es importante que exista la disposición de capital humano para que las actividades se desarrollen adecuadamente.

\section{Análisis de los emprendimientos en Ecuador antes de la pandemia}

- Datos estadísticos de Ecuador: como ya se había mencionado anteriormente en el año 2019 existió un gran crecimiento de emprendimientos en el Ecuador, esto era importante porque se estaba ayudando a reactivar la economía del país.

- Datos estadísticos de la provincia: en el Oro la situación era igual, puesto que a través del MIES el programa del Bono de Desarrollo Humano ayudaba con microcréditos que permitían a los ciudadanos poner en marcha sus emprendimientos, de esto un total de 342 emprendedores fueron beneficiados por este programa mencionado, estos pertenecientes a los cantones de Machala, El Guabo, Pasaje y Chilla. No todos estos emprendimientos lograron mantenerse en el mercado.

- Índice de nuevos emprendimientos en Ecuador: con el incremento acelerado de la pandemia muchos llegaron a pensar que tenían que abandonar sus sueños, por las dificultades y barreras que la propia enfermedad trajo consigo, algunos emprendimientos que habían surgido meses antes tuvieron que cerrar, pero otros han sido impulsados, por el mismo escenario, que les ha permitido reinventarse y sacar provecho de este momento para crecer y cumplir sus metas planteadas, según datos de la Superintendencia de Compañías, en Ecuador se registraron alrededor de 281 nuevos emprendimientos, situados en las provincias de El Oro, Pichincha, Azuay, Guayas y Manabí (MIES).

\section{Marketing}

Marketing es una ciencia, que se ha puesto en marcha desde hace mucho tiempo atrás, considerada como el proceso social y administrativo, donde las personas buscan la satisfacción de sus deseos y necesidades, promoviendo el desarrollo de la oferta y demanda, de algún producto o servicio.

El objetivo del marketing es analizar y explorar la necesidad de un individuo, para proceder agregar valor, mediante estrategias y tácticas que al ser bien aplicadas genera reconocimiento, preferencia y rentabilidad. 
Uno de los mitos más grandes es, "El Marketing se dedica a solo vender productos”, esto es un engaño, debido a que es una ciencia muy amplia donde se involucra tanto la producción, promoción, distribución, logística y comercialización, siendo el principal responsable para estudiar los comportamientos y necesidades de un grupo definido.

Para realizar una óptima estrategia, esta debe estar vinculada directamente al marketing mix o 4p's de marketing, Producto, plaza, precio y promoción (Thabit \& Raewf, 2018).

Producto: Es el punto de inicio del marketing, el producto debido a que es el encargado de satisfacer las necesidades de los futuros clientes, por lo que se debe conocer antes muy bien al consumidor para generar valor y una ventaja que sea competitiva ante los clientes.

Plaza: También llamado punto de venta, es el lugar donde se comercializa los productos o servicios, este sitio se debe elegirse estratégicamente para facilitar a los clientes el tiempo de busca de algún producto, mientras mejor este localizado una marca según su segmento, más rápido se posicionará en el mercado.

Precio: Es una decisión muy importante, para elegir un precio adecuado para nuestro producto, se debe estudiar, los costos fijos y variables, el mercado, la competencia y nuestro propio segmento a dirigirse.

Promoción: Son las acciones que la empresa realiza, para difundir y dar a conocer los beneficios de algún producto o marca.

\section{Marketing Digital}

El marketing digital se ha transformado en un método global para la comercialización, sin necesidad de ser parte de un proceso de trabajo convencional, ni mantener horarios rígidos que se convierten en carga para algunos trabajadores.

Se conoce que, con la evolución del internet, nos ha facilitado un sin número de herramientas que proporcionan el contacto con cualquier individuo, creando una nueva era en la comercialización "la era digital", que mediante algunos sistemas y procesos se consigue el objetivo de captar, conseguir clientes y finalizar ventas con tan solo un clic en una portátil o teléfono inteligente (López et al., 2018).

Entonces definamos al marketing digital como el conjunto de estrategias de mercadeo "que se desarrollan mediante el internet" pasando hacer el internet un factor importante, para facilitar la comunicación entre "cliente - empresa" e inversa. 


\section{Medios Digitales}

El internet es un mundo, una persona común conoce tan solo una mínima parte de todo este universo sin explorar, debido a esto al momento de elegir alguna estrategia digital, se debe olvidar de tan solo los canales digitales que conocemos y buscar la opción más óptima (Huapaya, 2020).

En el ámbito empresarial, si el internet es un universo, los medios digitales son las herramientas de visibilidad y posicionamiento en línea, realizando vínculos de amistad y confianza con nuestro clientes actuales y potenciales, comunicándose con un canal efectivo.

¿Cómo descubrir el canal óptimo para la estrategia de marketing?, es una pregunta importante antes del desarrollo de alguna estrategia, se deben conocer los medios y cómo influirá en los resultados que se obtengan, por lo tanto, se tiene que tener claro cuál es el segmento, el objetivo meta y a través de que medio digital se logrará alcanzarlo, puede darse el caso que el público objetivo no se encuentre en la red social más popular en el mundo (Sánchez \& Prenassi, 2017).

\section{Redes sociales}

Las redes sociales suman millones de usuarios diarios, que hoy en día solo una minoría en el mundo no se encuentra registrado en alguna red social, entonces es necesario utilizarlas como un intermediario, abriéndonos paso a una fase nueva pos mediática, de una sociedad donde el servicio y atención es más acelerado, personalizado, segmentada, instantánea, diluida, convergente, transparente, flexible, liviana, conversacional, interconectada y abocada a la colaboración, participación de todos los que se encuentran registrados de dichas Redes (Camana, 2020).

\section{Redes sociales en el Ecuador 2020}

Según Camana (2020) las redes sociales en Ecuador en el año 2020 han presentado los siguientes datos:

- Desde abril del 2019 a enero del 2020, en Ecuador aumentó el número de usuarios en redes sociales en un aproximado de 769 mil personas.

- Existe un total de 12 millones de usuarios en redes sociales. 
- Se realizaron en enero del 2020, 15.65 millones de conexiones mediante teléfonos móviles.

- Las conexiones por teléfonos móviles han disminuido desde enero del 2019 a enero del 2020 en un $6.8 \%$.

- La cifra de conexiones en teléfonos móviles existentes en el Ecuador equivale a un $89 \%$ de toda la población.

\section{Redes sociales más utilizadas en Ecuador}

En el Ecuador, en el 2020, la aplicación del WhatsApp es la red de mensajería de preferencia por parte de los ecuatorianos, pero al parecer ha llegado a su límite máximo, debido a que es la más utilizada, más no la que más crece (Corrales et al., 2017).

Tabla 2. Redes sociales más utilizadas en Ecuador

\begin{tabular}{|c|c|}
\hline Redes Sociales & Porcentaje \\
\hline Facebook & $54,4 \%$ \\
\hline WhatsApp & $52 \%$ \\
\hline Instagram & $18,2 \%$ \\
\hline YouTube & $15,4 \%$ \\
\hline Twitter & $8,8 \%$ \\
\hline
\end{tabular}

Fuente: Elaboración propia (Camana, 2020)

Como se puede ver en la tabla 1, Facebook es la red social más utilizada por los ecuatorianos teniendo un porcentaje del $54.4 \%$, de la misma manera le sigue WhatsApp e Instagram, sin embargo, Twitter es la red social menos utilizada la misma que abarca un $8.8 \%$ de la audiencia. Otros datos a considerar son los siguientes:

- Tik Tok, es una red social que está en crecimiento dentro del país.

- Facebook tiene usuarios de todas edades, pero predomina las edades entre 18 a 34 años de edad.

- Instagram su mayor cantidad de usuarios se encuentran entre 13 a 24 años de edad. 


\section{Estrategias promocionales en redes sociales}

Según Porter, 1999 las estrategias se las pueden definir como las actividades, que, al ponerse en acción, tienen como finalidad, el cumplimiento de los objetivos específicos, planteados en la planificación. A esta definición (Mintzberg \& Quinn, 2001) agregan que son modelos de decisiones donde se agrupan los principales objetivos, las políticas y serie de pasos o acciones que una empresa debe desenvolver, que cuando se plantean, planifican y desarrollan a cabalidad, resuelven dificultades en delimitaciones de recursos, en la competencia y deficiencias internas, como inconvenientes y nos ofrece nuevas oportunidades en el mercado (Torres et al., 2017). - Al momento de realizar una promoción, se debe tener en cuenta y conocer al nicho de mercado al que se está dirigiendo la empresa, una de las estrategias fundamentales en redes sociales, la creación de contenido, que no es otra cosa que ofrecer contenido de calidad atrayente para el usuario de nuestra preferencia, de tal manera que se convierta en audiencia para nuestra empresa (Espinoza et al.,2020).

- Personalizar las experiencias a los clientes es fundamental, mediante los chatbots que es un modo de automatizar algunas acciones, si se aplica correctamente a una estrategia de promoción, creara lazos de cercanía con el usuario.

- Crear presupuesto en redes sociales, se fundamenta en la gran competencia que existe dentro de redes sociales, muchos empresarios ofrecen el mismo o similar producto o servicio, entonces como destacar, o hacer mucho más visible nuestro emprendimiento, que el de la competencia, uno de los modos más efectivos es el pago de promoción dentro de redes, donde con un presupuesto bajo se garantiza la visualización de nuestras publicaciones a una audiencia segmentada.

- Sorteos o concursos, es una estrategia que abarca mucho reconocimiento e influencia de usuarios, donde usuarios etiquetan a otro usuario, para conseguir un obsequio que tenga valor para ese individuo, hay que tomar en cuenta que el obsequio debe de ser similar a lo que la empresa vende, para generar interés y obtener más seguidores y aumentar la audiencia en redes sociales.

\section{Estrategias de precios}

Las estrategias de precios contribuyen al cumplimiento de los objetivos de las empresas, para realizar una buena estrategia de precios se tiene de tomar en cuenta el tipo de producto que se comercializa, líneas del producto, la competencia, la economía del país y todos los factores que de alguna manera influyen al momento de elegir un precio, también un factor importante es la novedad del producto, mientras 
más innovador sea, mayores alternativas se tendrán al momento de elegir su precio y distintas estrategias de precios se pueden poner en marcha (Milan et al., 2016).

La dirección de marketing se encarga de elegir los precios, pero en micro empresas donde aún no se tiene una dirección de marketing, los precios son elegidos por el gerente o dueño de emprendimiento, al momento de establecer estos precios es de suma importancia los siguientes criterios:

- El objetivo empresarial

- La flexibilidad, la estrategia es adaptable al entorno y sus circunstancias.

- Orientación del mercado, se debe conocer muy bien los hábitos, comportamiento, necesidades, demanda y poder económico de sus potenciales consumidores

\section{Estrategias diferenciales}

Esta estrategia explota la heterogeneidad de segmento y consumidores, en busca de maximizar las ventas y beneficios, se basa en vender un mismo producto, pero a distintos precios, en función a la capacidad económica, factores sociodemográficos, obteniendo distintos precios en diversos segmentos de mercados diferentes (Remache, Lascano, \& Medina, 2018).

1. Estrategia de precios fijos o variables: Al elegir un precio fijo, significa que el producto se venderá al mismo precio sin importar las condiciones económicas u otro factor, teniendo las mismas condiciones de venta ante todo los clientes. Estos precios funcionan muy bien en los productos de compra masiva, de precios medios y bajos, se aplican independientemente del consumidor. Al tener un precio variable, implica más flexibilidad al momento de a venta y en sus condiciones. Este tipo de precio son habituales en productos costosos, casas, carros, etc.

2. Descuentos por cantidad: El descuento por cantidad, es cuando un comprador adquiere una cierta cantidad de productos superior a la normal, se le ofrece una reducción a su precio unitario, así motivando una compra en masa.

3. Descuento por pronto pago: Este descuento, es un bono que se le realiza a todos los compradores, que realizan sus pagos de manera inmediata o en el plazo de unos cortos días.

4. Aplazamiento del pago: Consiste en dar cuotas al cliente de forma, que se motive a adquirir un producto y lo pague en bajas cuotas, según su nivel económico y posibilidades. 
5. Descuentos aleatorios (ofertas): Es una de las estrategias de precios más utilizadas, especialmente en empresas que tienen un gran stock, reducen sus precios, dando descuento a clientes de manera que estimula la compra y una posible recompra, también es muy utilizada al momento de atraer nuevos clientes. Los descuentos pueden influir directamente en el precio, entrega de un producto complementario, $2 \times 1$, etc.

\section{Estrategias competitivas}

Los precios son fijados tomando en cuenta a los precios competidores, de manera de aprovecharse atrayendo al mercado y recaudar más que las empresas competidoras.

Existen tres tipos de estrategias competitivas, precios iguales, superiores e inferiores, también depende mucho de la calidad que ofrece en los productos, debido que, si se está ofertando un producto de calidad superior a sus competidores, podrá elevar sus precios, teniendo una estrategia de precios altos, dando más calidad por más precio, o mantener los precios de la competencia dando un resultado de más calidad, por precios similares (Shaadi Rodríguez \& Pulido Fernández, 2018).

Una estrategia de precios bajos, se supone que son productos con una calidad más baja que sus competidores, pero en caso de no ser así busca atraer y abarcar más clientes, que consiste en vender por debajo del equilibrio de los costos, de manera que obliga a la competencia a bajar precios y la elimina poco a poco.

\section{Metodología}

En la presente investigación se utilizó una metodología cualitativa, tomando como referencia la técnica de la entrevista, la misma que se aplicó a 10 emprendimientos que surgieron durante la pandemia con la finalidad de recabar información clave sobre los procesos, barreras y experiencias que se obtuvieron en el transcurso de estos 5 meses de pandemia.

Para el desarrollo de esta metodología se tomaron en consideración los siguientes puntos:

- Conocimientos básicos sobre como emprender: para determinar si los emprendedores previamente tenían conocimientos sobre emprender o si únicamente lo realizaron de manera empírica. 
- Idea de negocio: para saber por qué surgió la idea del negocio.

- COVID-19: oportunidad o amenaza: para detectar el punto de vista de los emprendedores.

- Dificultades y barreras: todo inicio de un emprendimiento se encuentra en el camino con barreras y dificultades que impiden el desarrollo en gran amplitud.

- Factor diferenciador (ventaja competitiva): para determinar el atributo clave para diferenciar un producto de la competencia en el segmento a dirigirse.

- Estrategias de marketing: actividades que al ponerse en acción tienen como finalidad cumplir objetivos específicos satisfaciendo una necesidad. Se tomará como referencia los medios, las promociones y el precio.

- Red social más importante: para determinar la red social que le permitió obtener mayor reconocimiento en el mercado.

- Experiencia obtenida: nos permitirá conocer que es lo que más les ha impactado a los emprendedores, o cuales son las situaciones de las que ellos han obtenido un aprendizaje en el desarrollo de su idea de negocio.

\section{Desarrollo de la metodología}

Se aplicaron entrevistas a los nuevos emprendimientos surgidos durante la pandemia, ante esto se obtuvieron los siguientes datos:

Tabla 3. Análisis de la entrevista

\begin{tabular}{|c|c|c|c|c|c|c|c|c|}
\hline Indicadores & Actividad & $\begin{array}{l}\text { Fecha de } \\
\text { inicio }\end{array}$ & $\begin{array}{l}\text { Conoci- } \\
\text { miento } \\
\text { sobre cóm }\end{array}$ & $\begin{array}{l}\text { Idea de } \\
\text { negocio }\end{array}$ & $\begin{array}{l}\text { Covid-19 } \\
\text { Oportu- } \\
\text { nidad o } \\
\text { amenaza }\end{array}$ & $\begin{array}{l}\text { Dificul- } \\
\text { tades y } \\
\text { barreras }\end{array}$ & $\begin{array}{l}\text { Factor di- } \\
\text { ferenciador } \\
\text { de la com- } \\
\text { petencia }\end{array}$ & $\begin{array}{l}\text { Expe- } \\
\text { riencias } \\
\text { obtenidas }\end{array}$ \\
\hline \multicolumn{9}{|l|}{$\begin{array}{l}\text { Emprendedores } \\
\text { Emprendi- } \\
\text { miento }\end{array}$} \\
\hline $\begin{array}{l}\text { Dennisse Picón } \\
\text { Alanita Shop }\end{array}$ & $\begin{array}{l}\text { Venta de } \\
\text { productos } \\
\text { varios. }\end{array}$ & Abril 2020 & $\begin{array}{l}\text { No poseía } \\
\text { conocimien- } \\
\text { tos sólidos. }\end{array}$ & $\begin{array}{l}\text { Surge por } \\
\text { complacer con } \\
\text { artículos pe- } \\
\text { queños ciertas } \\
\text { necesidades. }\end{array}$ & $\begin{array}{l}\text { Oportuni- } \\
\text { dad para } \\
\text { poder salir } \\
\text { adelante en } \\
\text { su idea de } \\
\text { negocio. }\end{array}$ & $\begin{array}{l}\text { Factor } \\
\text { económi- } \\
\text { co. }\end{array}$ & $\begin{array}{l}\text { El precio de } \\
\text { sus produc- } \\
\text { tos. }\end{array}$ & $\begin{array}{l}\text { No confiar } \\
\text { en los clien- } \\
\text { tes sin antes } \\
\text { recibir un } \\
\text { porcentaje } \\
\text { del dinero } \\
\text { por la com- } \\
\text { pra. }\end{array}$ \\
\hline
\end{tabular}




\begin{tabular}{|c|c|c|c|c|c|c|c|c|}
\hline $\begin{array}{l}\text { Beatriz Gam- } \\
\text { boa Mishelle } \\
\text { Ramón } \\
\text { Bymishur }\end{array}$ & $\begin{array}{l}\text { Realización } \\
\text { de postres. }\end{array}$ & $29 / 05 / 2020$ & $\begin{array}{l}\text { No poseía } \\
\text { conocimien- } \\
\text { tos. }\end{array}$ & $\begin{array}{l}\text { Por realizar al- } \\
\text { guna actividad } \\
\text { que le genere } \\
\text { ingresos. }\end{array}$ & $\begin{array}{l}\text { Oportuni- } \\
\text { dad para } \\
\text { buscar una } \\
\text { solución a } \\
\text { la situación } \\
\text { que atrave- } \\
\text { sábamos. }\end{array}$ & $\begin{array}{l}\text { Falta de } \\
\text { recursos, } \\
\text { movili- } \\
\text { zación e } \\
\text { inversión. }\end{array}$ & $\begin{array}{l}\text { Precios acce- } \\
\text { sibles. }\end{array}$ & $\begin{array}{l}\text { Comprender } \\
\text { como está } \\
\text { funcionando } \\
\text { el mercado } \\
\text { en estos } \\
\text { momentos. }\end{array}$ \\
\hline $\begin{array}{l}\text { Marina Soto- } \\
\text { mayor } \\
\text { Silvia Sánchez } \\
\text { Chivi's Banana }\end{array}$ & $\begin{array}{l}\text { Elabo- } \\
\text { ración y } \\
\text { venta de } \\
\text { chocoba- } \\
\text { nanas y } \\
\text { helados } \\
\text { artesanales. }\end{array}$ & $13 / 05 / 2020$ & $\begin{array}{l}\text { Sí, gracias a } \\
\text { la formación } \\
\text { profesional } \\
\text { de su her- } \\
\text { mana. }\end{array}$ & $\begin{array}{l}\text { Querer tomar } \\
\text { la iniciativa } \\
\text { de un negocio } \\
\text { similar que } \\
\text { tenían ante- } \\
\text { riormente. }\end{array}$ & $\begin{array}{l}\text { Oportuni- } \\
\text { dad porque } \\
\text { ayuda a } \\
\text { esforzarse } \\
\text { para lograr } \\
\text { los sueños. }\end{array}$ & $\begin{array}{l}\text { Daño de la } \\
\text { refrigera- } \\
\text { dora, lo } \\
\text { que impo- } \\
\text { sibilitaba } \\
\text { realizar los } \\
\text { productos. }\end{array}$ & $\begin{array}{l}\text { Variedad de } \\
\text { sabores. }\end{array}$ & $\begin{array}{l}\text { Dar lo mejor } \\
\text { de uno para } \\
\text { cumplir los } \\
\text { sueños y } \\
\text { las metas } \\
\text { propuestas. }\end{array}$ \\
\hline $\begin{array}{l}\text { Josselyn Aré- } \\
\text { valo } \\
\text { D'Patos }\end{array}$ & $\begin{array}{l}\text { Venta de } \\
\text { comida } \\
\text { rápida a } \\
\text { domicilio. }\end{array}$ & $02 / 05 / 2020$ & Sí & $\begin{array}{l}\text { Hace años } \\
\text { tenía esa idea, } \\
\text { pero su pudo } \\
\text { concretar por } \\
\text { la situación } \\
\text { económica. }\end{array}$ & $\begin{array}{l}\text { Oportuni- } \\
\text { dad por la } \\
\text { situación } \\
\text { económica } \\
\text { que vivi- } \\
\text { mos. }\end{array}$ & $\begin{array}{l}\text { No se } \\
\text { podía salir } \\
\text { libremente } \\
\text { a realizar } \\
\text { las com- } \\
\text { pras. }\end{array}$ & $\begin{array}{l}\text { Diferentes } \\
\text { opciones } \\
\text { para cada } \\
\text { semana. }\end{array}$ & $\begin{array}{l}\text { El generar } \\
\text { ingresos } \\
\text { desde casa y } \\
\text { satisfacer a } \\
\text { los consumi- } \\
\text { dores. }\end{array}$ \\
\hline $\begin{array}{l}\text { Servio Guzmán } \\
\text { Donutsplanet. } \\
\text { ec }\end{array}$ & $\begin{array}{l}\text { Venta de } \\
\text { donuts } \\
\text { personali- } \\
\text { zadas }\end{array}$ & $24 / 05 / 2020$ & $\begin{array}{l}\text { Sí, tuvo un } \\
\text { micro-em- } \\
\text { prendi- } \\
\text { miento hace } \\
\text { algunos } \\
\text { años. }\end{array}$ & $\begin{array}{l}\text { Por el tiempo } \\
\text { libre que tenía } \\
\text { debido a la } \\
\text { pandemia. }\end{array}$ & $\begin{array}{l}\text { Oportuni- } \\
\text { dad para } \\
\text { emprender. }\end{array}$ & $\begin{array}{l}\text { Duda, des- } \\
\text { confianza, } \\
\text { temor al } \\
\text { fracaso. }\end{array}$ & $\begin{array}{l}\text { A más de } \\
\text { vender un } \\
\text { producto, } \\
\text { venden } \\
\text { emociones y } \\
\text { experiencias. }\end{array}$ & $\begin{array}{l}\text { De a poco se } \\
\text { puede crecer } \\
\text { y desarrollar } \\
\text { un empren- } \\
\text { dimiento, } \\
\text { además } \\
\text { tratar a los } \\
\text { clientes } \\
\text { amable y cor- } \\
\text { dialmente. }\end{array}$ \\
\hline $\begin{array}{l}\text { Erika Sánchez } \\
\text { Erika Rocío } \\
\text { Lencería }\end{array}$ & $\begin{array}{l}\text { Diseño y } \\
\text { confección } \\
\text { de lencería }\end{array}$ & $15 / 06 / 2020$ & Sí & $\begin{array}{l}\text { Para poner en } \\
\text { práctica los } \\
\text { conocimientos } \\
\text { obtenidos de } \\
\text { forma empí- } \\
\text { rica. }\end{array}$ & $\begin{array}{l}\text { Oportuni- } \\
\text { dad, porque } \\
\text { aprovechó } \\
\text { al máximo } \\
\text { el tiempo } \\
\text { de estar en } \\
\text { casa para } \\
\text { diseñar. }\end{array}$ & $\begin{array}{l}\text { Dificultad } \\
\text { económica } \\
\text { para ad- } \\
\text { quirir una } \\
\text { máquina } \\
\text { industrial } \\
\text { de costura. }\end{array}$ & $\begin{array}{l}\text { La forma } \\
\text { en la que el } \\
\text { cliente recibe } \\
\text { sus produc- } \\
\text { tos. }\end{array}$ & $\begin{array}{l}\text { Que mante- } \\
\text { ner una red } \\
\text { social activa } \\
\text { ayuda a } \\
\text { producir más } \\
\text { ventas. }\end{array}$ \\
\hline
\end{tabular}




\begin{tabular}{|c|c|c|c|c|c|c|c|c|}
\hline $\begin{array}{l}\text { Edinson Vala- } \\
\text { rezo } \\
\text { Nativos }\end{array}$ & $\begin{array}{l}\text { Elabora- } \\
\text { ción de } \\
\text { diseños } \\
\text { gráficos } \\
\text { para } \\
\text { microem- } \\
\text { presas }\end{array}$ & $10 / 02 / 2020$ & $\begin{array}{l}\text { Sólo cono- } \\
\text { cimientos } \\
\text { teóricos. }\end{array}$ & $\begin{array}{l}\text { Porque le agra- } \\
\text { da el diseño } \\
\text { gráfico. }\end{array}$ & $\begin{array}{l}\text { Oportuni- } \\
\text { dad, puesto } \\
\text { que varias } \\
\text { empresas } \\
\text { quisieron } \\
\text { pautarse }\end{array}$ & $\begin{array}{l}\text { No tuvo } \\
\text { barreras, } \\
\text { todo } \\
\text { fue por } \\
\text { medios } \\
\text { digitales. }\end{array}$ & $\begin{array}{l}\text { Calidad en } \\
\text { los servicios } \\
\text { ofrecidos. }\end{array}$ & $\begin{array}{l}\text { Descubrir } \\
\text { cómo se } \\
\text { maneja el } \\
\text { mercado y } \\
\text { como actúa } \\
\text { el cliente en } \\
\text { su decisión } \\
\text { de compra. }\end{array}$ \\
\hline $\begin{array}{l}\text { Evelyn Armijos } \\
\text { Tiny Store }\end{array}$ & $\begin{array}{l}\text { Venta de } \\
\text { kits de } \\
\text { belleza }\end{array}$ & $15 / 06 / 2020$ & Sí & $\begin{array}{l}\text { Por un proble- } \\
\text { ma usual de las } \\
\text { mujeres. }\end{array}$ & Amenaza & $\begin{array}{l}\text { La com- } \\
\text { petencia } \\
\text { tiene tien- } \\
\text { das online } \\
\text { y variedad } \\
\text { de precios. }\end{array}$ & $\begin{array}{l}\text { La calidad en } \\
\text { los productos } \\
\text { que ofrece. }\end{array}$ & $\begin{array}{l}\text { Conocer al } \\
\text { cliente. }\end{array}$ \\
\hline $\begin{array}{l}\text { Nancy Galarza } \\
\text { Viki's Gour- } \\
\text { mette }\end{array}$ & $\begin{array}{l}\text { Venta de } \\
\text { almuerzos, } \\
\text { lasañas y } \\
\text { postres }\end{array}$ & $20 / 04 / 2020$ & $\begin{array}{l}\text { Sí, los apren- } \\
\text { dió en la } \\
\text { universidad. }\end{array}$ & $\begin{array}{l}\text { Por la situa- } \\
\text { ción que se } \\
\text { está viviendo } \\
\text { en el país. }\end{array}$ & $\begin{array}{l}\text { Oportu- } \\
\text { nidad, } \\
\text { porque ha } \\
\text { despertado } \\
\text { las ganas de } \\
\text { empren- } \\
\text { der en las } \\
\text { personas. }\end{array}$ & $\begin{array}{l}\text { Por el } \\
\text { Covid las } \\
\text { personas } \\
\text { tenían } \\
\text { recelo } \\
\text { comprar } \\
\text { comida } \\
\text { preparada. }\end{array}$ & $\begin{array}{l}\text { La pasta para } \\
\text { la lasaña es } \\
\text { elaborada } \\
\text { de manera } \\
\text { artesanal. }\end{array}$ & $\begin{array}{l}\text { Experien- } \\
\text { cia que ha } \\
\text { marcado su } \\
\text { vida, no ima- } \\
\text { ginó realizar } \\
\text { postres o } \\
\text { lasañas. }\end{array}$ \\
\hline $\begin{array}{l}\text { Seguridad y } \\
\text { calidad alimen- } \\
\text { taria } \\
\text { "Secal" }\end{array}$ & $\begin{array}{l}\text { Asesorías } \\
\text { profesio- } \\
\text { nales en la } \\
\text { industria } \\
\text { de los } \\
\text { alimentos, } \\
\text { emitiendo } \\
\text { registros } \\
\text { sanitarios, } \\
\text { capaci- } \\
\text { taciones } \\
\text { técnicas, } \\
\text { controles } \\
\text { de plaga, } \\
\text { venta de } \\
\text { insumos, } \\
\text { de mate- } \\
\text { riales, de } \\
\text { equipo. }\end{array}$ & $05 / 07 / 2020$ & $\begin{array}{l}\text { Una breve } \\
\text { idea, el } \\
\text { mundo de } \\
\text { emprender } \\
\text { es muy } \\
\text { amplio y se } \\
\text { aprende de } \\
\text { los errores } \\
\text { que se van } \\
\text { cometiendo. }\end{array}$ & $\begin{array}{l}\text { Surge en } \\
\text { un antiguo } \\
\text { trabajo, donde } \\
\text { existían algu- } \\
\text { nas falencias } \\
\text { y necesidades, } \\
\text { y se realiza la } \\
\text { pregunta ¿Por } \\
\text { qué no existe } \\
\text { una empresa } \\
\text { que satisfaga } \\
\text { esa necesidad } \\
\text { aquí en Ma- } \\
\text { chala? }\end{array}$ & $\begin{array}{l}\text { Lo consi- } \\
\text { dero como } \\
\text { una amena- } \\
\text { za, debido } \\
\text { a que ellos } \\
\text { traba- } \\
\text { jan con } \\
\text { empresas y } \\
\text { debido a la } \\
\text { enfermedad } \\
\text { muchas } \\
\text { empresas } \\
\text { están } \\
\text { cerrando. }\end{array}$ & $\begin{array}{l}\text { Una barre- } \\
\text { ra existió } \\
\text { en la com- } \\
\text { petencia, } \\
\text { competir } \\
\text { con } \\
\text { empresas } \\
\text { grandes y } \\
\text { estableci- } \\
\text { das. }\end{array}$ & $\begin{array}{l}\text { La capa- } \\
\text { citación y } \\
\text { especializa- } \\
\text { ción, ofrecer } \\
\text { combos no } \\
\text { solo quedarse } \\
\text { en asesorías. }\end{array}$ & $\begin{array}{l}\text { Recién } \\
\text { obtuvo una } \\
\text { experiencia } \\
\text { en un centro } \\
\text { comercial } \\
\text { grande de la } \\
\text { ciudad, don- } \\
\text { de oferto el } \\
\text { servicio que } \\
\text { ofrece, pero } \\
\text { no lo acep- } \\
\text { taron debido } \\
\text { a falta de } \\
\text { certificación } \\
\text { y gracias a } \\
\text { la perseve- } \\
\text { rancia hoy } \\
\text { en día ya se } \\
\text { encuentra } \\
\text { certificado. }\end{array}$ \\
\hline
\end{tabular}

\section{Fuente: Entrevista aplicada a los nuevos emprendimientos Elaboración: Ximena Pereira; Edinson Valarezo}


Tabla 4. Estrategias de marketing en los nuevos emprendimientos

\begin{tabular}{|c|c|c|c|c|c|}
\hline Indicadores & Medios & $\begin{array}{l}\text { Las redes sociales o juegan o } \\
\text { están jugando un papel }\end{array}$ & $\begin{array}{l}\text { Importante para su } \\
\text { éxito }\end{array}$ & Promociones & Precios \\
\hline \multicolumn{6}{|l|}{$\begin{array}{l}\text { Emprendedores } \\
\text { Emprendimiento }\end{array}$} \\
\hline $\begin{array}{l}\text { Dennisse Picón } \\
\text { Alanita Shop }\end{array}$ & Redes sociales & $\begin{array}{l}\text { Sí, tienen gran influencia, } \\
\text { atraen más clientes. }\end{array}$ & Instagram & $\begin{array}{l}\text { Sorteos } 2 \text { productos } \\
\text { por un precio } \\
\text { accesible. }\end{array}$ & $\begin{array}{l}\text { Accesibles } \\
\text { Precios bajos }\end{array}$ \\
\hline $\begin{array}{l}\text { Beatriz Gamboa } \\
\text { Mishelle Ramón } \\
\text { Bymishur }\end{array}$ & $\begin{array}{l}\text { Instagram, } \\
\text { Marketplace, } \\
\text { Facebook }\end{array}$ & $\begin{array}{l}\text { Sí, porque es un medio que } \\
\text { ayuda al alcance de nuevos } \\
\text { clientes. }\end{array}$ & $\begin{array}{l}\text { Facebook (Marke- } \\
\text { tplace) }\end{array}$ & $\begin{array}{l}\text { Promociones para } \\
\text { tiendas de barrio. } \\
\text { Por la compra de } \\
3 \text { o más productos } \\
\text { se obsequia una } \\
\text { pulsera de la marca } \\
\text { Bymishur }\end{array}$ & Desde $\$ 2,00$ \\
\hline $\begin{array}{l}\text { Marina Sotomayor } \\
\text { Silvia Sánchez } \\
\text { Chivi's Banana }\end{array}$ & $\begin{array}{l}\text { Instagram, } \\
\text { Facebook, } \\
\text { WhatsApp } \\
\text { Lonas publici- } \\
\text { tarias } \\
\text { Recomendacio- } \\
\text { nes y publicidad } \\
\text { entre familiares } \\
\text { y amigos. }\end{array}$ & $\begin{array}{l}\text { Sí, porque son el medio } \\
\text { más rápido para encontrar } \\
\text { información. }\end{array}$ & Instagram & $\begin{array}{l}\text { Sábados envíos sin } \\
\text { recargo. } \\
\text { Miércoles y jueves: } \\
\text { compra } 4 \text { choco- } \\
\text { bananas y lleva } 2 \\
\text { originales gratis. }\end{array}$ & $\begin{array}{l}\text { Chocobanas } \\
\$ 0,30 \text { - } \$ 0,50 \\
\text { - } \$ 0,75 \text { y en } \\
\text { helados } \$ 0,50 \text { - } \\
\$ 0,75 \\
\text { Bandejita con } \\
\text { los } 16 \text { sabores a } \\
\$ 6,00\end{array}$ \\
\hline $\begin{array}{l}\text { Josselyn Arévalo } \\
\text { D’Patos }\end{array}$ & $\begin{array}{l}\text { Redes sociales } \\
\text { Publicidad }\end{array}$ & $\begin{array}{l}\text { Sí, porque permiten } \\
\text { promocionar nuestros } \\
\text { negocios. }\end{array}$ & $\begin{array}{l}\text { WhatsApp y } \\
\text { Facebook }\end{array}$ & $\begin{array}{l}\text { Combos con } \\
\text { bebidas gratis }\end{array}$ & $\begin{array}{l}\text { Precios accesi- } \\
\text { bles, no pasan } \\
\text { de los } \$ 5,00 \text {. }\end{array}$ \\
\hline $\begin{array}{l}\text { Servio Guzmán } \\
\text { Donutsplanet.ec }\end{array}$ & $\begin{array}{l}\text { Redes socia- } \\
\text { les. }\end{array}$ & $\begin{array}{l}\text { Sí, porque permiten que } \\
\text { los pequeños emprendi- } \\
\text { mientos y las grandes em- } \\
\text { presas utilicen herramien- } \\
\text { tas de marketing digital. }\end{array}$ & $\begin{array}{l}\text { Instagram y } \\
\text { WhatsApp }\end{array}$ & $\begin{array}{l}2 \text { do a mitad de } \\
\text { precio. } \\
\text { Productos gratis } \\
\text { por cada compra, } \\
\text { entre otros. }\end{array}$ & $\begin{array}{l}\text { Precios módi- } \\
\text { cos, van desde } \\
\text { los } \$ 4,99 \text { hasta } \\
\text { los } \$ 20 \text {. }\end{array}$ \\
\hline $\begin{array}{l}\text { Erika Sánchez } \\
\text { Erika Rocío } \\
\text { Lencería }\end{array}$ & Instagram & $\begin{array}{l}\text { Sí, porque hoy en día } \\
\text { nos encontramos en un } \\
\text { universo completamente } \\
\text { digital. }\end{array}$ & Instagram & $\begin{array}{l}\text { No se aplican } \\
\text { promociones. }\end{array}$ & $\begin{array}{l}\text { Varían de } \\
\text { acuerdo al di- } \\
\text { seño, el rango } \\
\text { está entre } \$ 15 \\
\text { y\$40. }\end{array}$ \\
\hline
\end{tabular}




\begin{tabular}{|c|c|c|c|c|c|}
\hline $\begin{array}{l}\text { Edinson Valarezo } \\
\text { Nativos }\end{array}$ & $\begin{array}{l}\text { Redes socia- } \\
\text { les: Facebook, } \\
\text { Instagram y } \\
\text { WhatsApp. } \\
\text { Recomenda- } \\
\text { ciones boca } \\
\text { a boca de los } \\
\text { clientes. }\end{array}$ & $\begin{array}{l}\text { Sí, porque debido al } \\
\text { distanciamiento social las } \\
\text { personas no han podi- } \\
\text { do visitar las empresas, } \\
\text { motivo por el cual las } \\
\text { actividades se desarrollan } \\
\text { en redes sociales. }\end{array}$ & Facebook & $\begin{array}{l}\text { Promoción para } \\
\text { clientes nuevos: } \\
\text { por realizar el } \\
\text { primer diseño el } \\
\text { segundo es gratis. }\end{array}$ & $\begin{array}{l}\text { Descuento en } \\
\text { el precio. }\end{array}$ \\
\hline $\begin{array}{l}\text { Evelyn Armijos } \\
\text { Tiny Store }\end{array}$ & $\begin{array}{l}\text { Redes socia- } \\
\text { les: Facebook, } \\
\text { Instagram y } \\
\text { WhatsApp. }\end{array}$ & $\begin{array}{l}\text { Sí, porque con la pan- } \\
\text { demia las personas usan } \\
\text { mucho las redes sociales. }\end{array}$ & Facebook & $\begin{array}{l}\text { Rebajas en el } \\
\text { valor inicial } \\
\text { como apertura } \\
\text { del producto en } \\
\text { la tienda. }\end{array}$ & $\begin{array}{l}\text { Precios que } \\
\text { van desde los } \\
\$ 2,00 \text { hasta los } \\
\$ 40,00 .\end{array}$ \\
\hline $\begin{array}{l}\text { Nancy Galarza } \\
\text { Viki's Gourmette }\end{array}$ & Redes sociales & $\begin{array}{l}\text { Sí, hoy en día son muy } \\
\text { utilizadas y se logra ven- } \\
\text { der si se usan correcta- } \\
\text { mente. }\end{array}$ & Instagram & $\begin{array}{l}\text { Por la compra de } \\
8 \text { bolitos de } \$ 0,50 \\
\text { el envío es gratis. }\end{array}$ & $\begin{array}{l}\text { Lasaña perso- } \\
\text { nal: } \$ 3,50 \\
\text { Lasaña fami- } \\
\text { liar: } \$ 17,50 \\
\text { Bolos: } \$ 0,50 \\
\text { Chocobanana: } \\
\$ 0,50 \\
\text { Tiramisú: } \$ 2,50 \\
\text { Queso de } \\
\text { leche: } \$ 1,00\end{array}$ \\
\hline $\begin{array}{l}\text { Ing. Erik Vivanco } \\
\text { Seguridad y cali- } \\
\text { dad alimentaria } \\
\text { "Secal" }\end{array}$ & $\begin{array}{l}\text { Medios vir- } \\
\text { tuales } \\
\text { Zoom } \\
\text { Redes sociales }\end{array}$ & $\begin{array}{l}\mathrm{Si} \text {, debido a que todo el } \\
\text { mundo maneja redes } \\
\text { sociales }\end{array}$ & Instagram & $\begin{array}{l}\text { Promociones } \\
\text { en agrupación } \\
\text { de servicio o } \\
\text { combos. }\end{array}$ & $\begin{array}{l}\text { Por la compra } \\
\text { de un pro- } \\
\text { ducto, obtiene } \\
\text { extra uno en } \\
\text { menor precio o } \\
\text { en caso gratis. }\end{array}$ \\
\hline
\end{tabular}

Fuente: Entrevista aplicada a los nuevos emprendimientos

Elaboración: Ximena Pereira; Edinson Valarezo

\section{Resultados}

De acuerdo a los datos obtenidos de la entrevista aplicada a los nuevos emprendedores, se ha podido determinar, que gran parte de ellos, tuvieron el inicio de sus actividades comerciales a principios de este año, en los meses de abril y junio, meses en los cuales se expandió la pandemia hasta Ecuador. Ante esto es importante indicar que en la investigación se analiza que los emprendedores tenían conocimientos teóricos sobre como emprender, sin embargo, una pequeña parte ya poseía experiencia en el ámbito laboral, puesto que anteriormente contaban con un emprendimiento. Estos emprendimientos surgieron por diferentes causas siendo 
estas: satisfacer una necesidad propia de autorrealización, también para generar un ingreso extra por la situación que está pasando en estos momentos, así mismo algunos fueron ideas planteadas en el pasado pero que por cuestiones de tiempo y dinero no se pudieron concretar.

La pandemia, la cual ha sido una amenaza para el mundo entero, se ha convertido en una oportunidad para los nuevos emprendedores, porque les ha abierto las puertas para involucrarse en este mundo del emprendimiento y determinar así las necesidades del mercado. Pero no todo ha sido fácil en su caminar, porque en el desarrollo de sus actividades también se han encontrado con barreras y dificultades que les han impedido desenvolverse de la manera que quizás ellos esperaban, debido a las precauciones tomadas en el país hacia el COVID-19, no contaban con los medios necesarios para transportar o comprar los recursos básicos indispensables para la producción o entrega de productos o servicios.

Se analizaron algunas maneras para diferenciarse en el mercado por parte de estos emprendedores, en donde dependía del sector al cual se dirigen, algunos apostando como atributo o ventaja diferenciadora una extensa línea de productos con diversos precios accesibles en el mercado, otro punto importante es la calidad, las experiencias y emociones que el producto o servicio ofrece y no es percibida por parte de los clientes en la competencia, adicionalmente unas empresas tuvieron una ventaja en sus procesos de producción donde elaboraron productos artesanales y $100 \%$ caseros.

Partiendo del análisis de la entrevista aplicada, se ha podido determinar que los nuevos emprendedores en su mayoría se decidieron, por una de las estrategias, que ha cobrado auge en los últimos tiempos, como las redes sociales y medios digitales para dar a conocer sus negocios, algunos de ellos también utilizaron medios publicitarios como lonas fuera de su casa y las recomendaciones boca a boca de sus familiares y amigos, cabe indicar que para ellos las redes sociales están jugando un papel muy importante porque les permite tener un mayor alcance y visualización segmentada de su producto o servicio ofrecido, siendo una magnifica opción, debido a las leyes de cuarentena adoptadas en el país, en donde la gran mayoría de personas se acopla y pasa gran parte de su tiempo en casa, utilizando sus redes sociales ya sea por trabajo o entretenimiento. Los emprendedores han elegido diferentes tipos de redes sociales según el segmento hacia el cual se dirigen y en donde se encuentra gran parte de su segmento, entre las cuales se encuentran Instagram y Facebook.

Al momento de establecer los precios por parte de los emprendedores, se analiza 
que ellos trabajan con precios bajos, sin embargo, en las promociones se aplican descuentos por volúmenes de compra, combos y por cierta cantidad de compra el envío es gratis. De todo este proceso los emprendedores han obtenido como experiencia el conocer más a sus clientes y el mercado en el que se están desenvolviendo, también es gratificante para ellos ver como de a poco se cumplen sus sueños y pueden ir construyendo un negocio sólido y reconocido en la ciudad.

\section{Conclusiones}

Según los resultados obtenidos en el estudio, se concluye que, el emprendedor es un individuo que ha sabido adaptarse a las condiciones del mercado, debido a la situación que transcurre en el Ecuador y el mundo, dándose a conocer como una persona capaz de convertir una amenaza en una oportunidad, encontrando nuevas necesidades en clientes y satisfaciéndolas con la ayuda de medios digitales que no eran de suma importancia al momento de comercializar antes de esta pandemia.

Para los emprendedores no todo ha sido fácil, al inicio del desarrollo de sus actividades económicas encontraron ciertas barreras en el mercado tales como la inseguridad, falta de recursos o de maquinaria para la producción, sin embargo, sus ganas de superación personal les ayudaron a enfrentar cada situación, esto porque las ideas del negocio surgieron por motivación propia, por generar un ingreso extra y por la situación económica que atraviesa el país.

Algunos de los emprendedores únicamente tenían conocimientos teóricos sobre cómo emprender, mientras algunos posteriormente habían tenido otros emprendimientos y por ende conocían la dificultad al momento de emprender, sin importar la experiencia de cada uno, es destacable la preferencia que tienen hacia las redes sociales, la publicidad y la recomendación boca a boca como estrategias de marketing para darse a conocer en sus inicios en un mercado competitivo.

Entre las redes sociales más importantes para su éxito en el mercado se encuentran Facebook e Instagram, para esto se diferencian de la competencia estableciendo precios accesibles a sus clientes y aplicando descuentos ya sea por volúmenes de compra o entregas a domicilio.

Este estudio ha permito que se conozcan los pro y contras que han tenido los emprendedores al momento de desarrollar sus actividades, pero de la misma manera se ha podido analizar cómo ellos no se detuvieron ante las circunstancias, pues su 
finalidad es poder cumplir sus sueños y llegar a tener reconocimiento tanto local como nacionalmente.

Frente a esto es importante como investigadores recomendar a los emprendedores no dejarse vencer por las barreras que encuentren en el camino, y aprovechar que las redes sociales son un medio masivo de comunicación siendo este el lugar idóneo para que la audiencia pueda conocer la oferta de sus productos, además tienen un gran alcance ofreciéndoles mayores ventajas, también deben analizar bien las promociones que apliquen, porque son una forma de enganche con los clientes, la selección adecuada de precios es fundamental, considerando precios que se encuentren al alcance del público objetivo, tomando en consideración que la pandemia ha afectado la economía de todos los ecuatorianos.

Finalmente se recomienda realizar futuras investigaciones sobre la profundización de la utilización de redes sociales en pequeñas y grandes empresas.

\section{Referencias bibliográficas}

Alemany, L., Álvarez, C., Planillas, M., \& Urbano, D. (2011). Libro Blanco de la iniciativa emprendedora en España. Barcelona: ESADE.

Camana, R. (2020). Redes sociales más usadas en Ecuador. Expreso. Obtenido de https://www.expreso.ec/opinion/carta-de-lectores/redes-sociales-usadas-ecuador-89617.html

Chirinos, Y., Meriño, V., \& Martínez, C. (2018). El clima organizacional en el emprendimiento sostenible. Revista Escuela De Administración De Negocios.(84), 43-61. doi:https://doi.org/10.21158/01208160.n84.2018.1916

Corrales, A., Coque, L., \& Brazales, Y. (2017). El marketing digital y su influencia en la administración empresarial. Dominio de las Ciencias, 3(4), 1161-1171. Obtenido de https://dialnet.unirioja.es/servlet/articulo?codigo=6325485

Eluniversocom. (27 de Julio de 2020). 82 \% de ecuatorianos emprenden por falta de empleo y otros por marcar una diferencia. $82 \%$ de ecuatorianos emprenden por falta de empleo y otros por marcar una diferencia. https://www.eluniverso.com/noticias/2020/07/23/nota/7916634/emprendimientos-empleo-desempleo-necesidad-ecuador/ 
Espinoza, F., García, J., Pita, G., \& Patiño, E. (2020). La creación de fanpage en el desarrollo de emprendimientos locales. Revista San Gregorio, 38. Obtenido de http://www.revista.sangregorio.edu.ec/index.php/REVISTASANGREGORIO/ article/view/1197/10-XAVIER

Huapaya, C. (2020). Estudio de caso de las estrategias de publicidad digital de los emprendimientos de repostería saludable" Fit cake" y" Un dulce con Cami” creados durante mayo-agosto en el contexto del Covid-19 en Lima Metropolitana.

Jácome, I., Tinajero, M., \& Suárez, I. (2018). Características del comportamiento emprendedor en estudiantes egresados universitarios del Ecuador. Revista Científica Dominio de las Ciencias., 4(3), 163-176. Obtenido de https://dialnet. unirioja.es/servlet/articulo?codigo $=6560193$

Kemp, S. (17 de Febrero de 2020). Datareportal. Obtenido de Datareportal: https://datareportal.com/reports/digital-2020-ecuador

López, O., Beltrán, C., Morales, R., \& Cavero, O. (2018). Estrategias de marketing digital por medio de redes sociales en el contexto de las PYMES del Ecuador. CienciAmérica: Revista de divulgación científica de la Universidad Tecnológica Indoamérica, 7(2), 39-56. Obtenido de https://dialnet.unirioja.es/servlet/articulo? codigo $=6553438$

Martínez, C., \& Bañón, A. (2020). Emprendimiento en épocas de crisis: Un análisis exploratorio de los efectos de la COVID-19. Small Business International Review, 4(2), 53-66.

MIES. (s.f.). Ministerio de Inclusión Económica y Social. Obtenido de Ministerio de Inclusión Económica y Social: https:/www.inclusion.gob.ec/342-emprendedores-de-el-oro-crecen-con-el-credito-de-desarrollo-humano/

Milan, G., Saciloto, E., Larentis, F., \& De Toni, D. (2016). Las estrategias de precios y el desempeño de las empresas. REAd. Revista Eletrônica de Administração (Porto Alegre), 22(2), 419-452. Obtenido de https://www.scielo.br/scielo.php?scrip$\mathrm{t}=\mathrm{sci}$ _arttext\&pid=S1413-23112016000200419\&lng=pt\&tlng=pt

Mintzberg, H., \& Quinn, J. (2001). O processo da estratégia. Bookman, Porto Alegre 
Murulanda, F., Montoya, I., \& Vélez, J. (2019). El Individuo y sus motivaciones en el proceso emprendedor. Universidad \& Empresa, 21(36), 149-174. doi:https://doi.org/10.12804/revistas.urosario.edu.co/empresa/a.6197

OIT. (Mayo de 2020). OIT Para Países Andinos. Obtenido de OIT Para Países Andinos: https://www.ilo.org/wcmsp5/groups/public/---americas/---ro-lima/ documents/publication/wcms_745271.pdf

Planificación.gob. (2020). Evaluación socioeconómica PDNA COVID-19. Obtenido de Evaluación socioeconómica PDNA COVID-19: https://www.planificacion. gob.ec/wp-content/uploads/downloads/2020/12/Eval-Soc-Econ-10-Dic-ok.pdf

Porter, M. (1999). Competição on competition. Estratégias competitivas. . Campus, Rio de Janeiro .

Remache, A., Lascano, M., \& Medina, R. (2018). Estrategia de marketing basada en el uso de Instagram para la publicidad de ropa interior en Tungurahua, Ecuador. Ricea, 7 (14), 1-28. doi:10.23913/ricea.v7i14.115

Rodríguez, V., Reina, C., Rodríguez, K., \& Cañarte, L. (2020). Nuevos emprendimientos: Un análisis a sus tipos y posicionamiento postcovid-19. Revista Científica FIPCAEC (Fomento de la investigación y publicación en Ciencias Administrativas, Económicas y Contables)., 5, 91-113.

Sánchez, M., \& Prenassi, M. (2017). Redes Sociales de Emprendedores de la Ciudad de Bahía Blanca, Argentina. En RIDCA, 43-63. http://200.49.237.216/ bitstream/123456789/4474/3/Redes\%20sociales\%20de\%20emprendedores.pdf

Schumpeter, J. (2012). Historia del análisis económico. España : Editorial Ariel .

Shaadi Rodríguez, R., \& Pulido Fernández, J. (2018). La consolidación turística en los territorios que conforman el Programa Pueblos Mágicos (México). Un análisis de sus estrategias competitivas. RUA Revista Investigaciones Turísticas, no 15, 1-33. https://rua.ua.es/dspace/bitstream/10045/76668/1/Investigaciones-Turisticas_15_01.pdf

Thabit, T., \& Raewf, M. (2018). La evaluación de los elementos del marketing mix: un estudio de caso. Revista internacional de ciencias sociales y estudios educativos, 4 (4). https://papers.ssrn.com/sol3/papers.cfm?abstract_id=3173274 
Torres, R., Rivera, J., Cabarcas, R., \& Castro, Y. (2017). a efectividad del uso del marketing digital como estrategia para el posicionamiento de las pymes para el sector comercio en la ciudad de Barranquilla. Investigación y Desarrollo en TIC, 8(2), 3-5.. http://revistas.unisimon.edu.co/index.php/identic/article/download/2947/3443

Vélez, X., \& Ortiz, S. (2016). Emprendimiento e innovación: Una aproximación teórica. Revista Científica Dominio de las Ciencias., 2(4), 346-369. https://dialnet. unirioja.es/descarga/articulo/5802889.pdf

Vera, J., Vera, A., \& Parrales, M. (2020). Crisis economica en Ecuador: una mirada al sector microempresarial post COVID-19. Revista Científica Multidisciplinaria, $4(4), 1-14$.

Zamora, C. (2018). La importancia del emprendimiento en la economía: el caso de Ecuador. Revista Espacios., 39(07), 1-15. Obtenido de https://www.researchgate. net/profile/Clarisa_Zamora/publication/326986184_La_importancia_del_emprendimiento_en_la_economia_el_caso_de_Ecuador/links/5b70b2a492851ca$65056 \mathrm{~d} 6 \mathrm{de} /$ La-importancia-del-emprendimiento-en-la-economia-el-caso-de-Ecuador.pdf 
Universidad Técnica de Machala

Dirección de Investigación

\section{Editorial UTMACH}

https://investigacion.utmachala.edu.ec/portal/

Primera edición 2021

Colección Semana de la Ciencia

PDF interactivo 



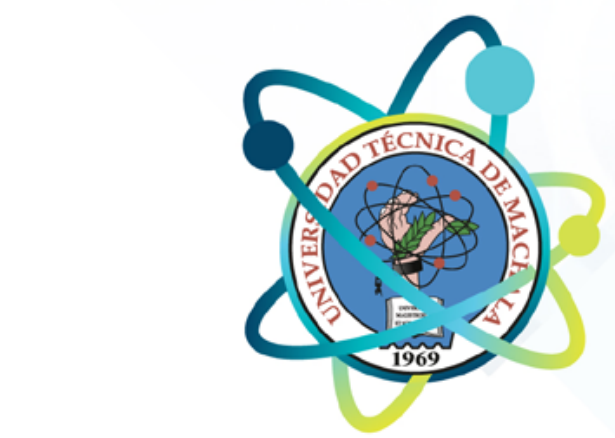

\section{Investigación UTMACH}

2021

Km. 5 1/2 Machala - Pasaje

Teléfono: (593) 72933345 Ext. 173

E-mail: editorial@utmachala.edu.ec investigacion.utmachala.edu.ec 